\title{
Práticas do cuidador informal do idoso no domicílio
}

\author{
Practices of elderly's informal caregiver at home \\ Prácticas del cuidador informal del anciano en el domicilio
}

\section{Chrystiany Plácido de Brito Vieira', Ana Virgínia de Melo Fialho', Consuelo Helena Aires de Freitas', Maria Salete Bessa Jorge'}

\author{
'Universidade Estadual do Ceará. Departamento de Enfermagem. \\ Mestrado Acadêmico Cuidados Clínicos em Saúde. Fortaleza-CE, Brasil.
}

Submissão: 21/09/2009 Aprovação: 19/06/2010

\section{RESUMO}

Objetivou-se analisar a produção científica da Enfermagem brasileira, de 1979 a 2007, sobre as práticas do cuidador informal do idoso no domicílio. Trata-se de revisão bibliográfica, com abordagem qualitativa, desenvolvida em junho e julho de 2009, que estudou teses e dissertações publicadas nos catálogos do Centro de Estudos e Pesquisas em Enfermagem (CEPEn). Utilizou-se o sistema de categorização temática para a análise dos dados. Dos onze trabalhos levantados, chegou-se a quatro categorias: atividades realizadas pelo cuidador, dificuldades no cotidiano do cuidar, sentimentos vivenciados pelo cuidador e conhecimentos e experiências do cuidador. O conhecimento da atuação desses cuidadores é de fundamental importância para as ações do enfermeiro e da equipe de saúde, dirigindo o cuidado não só ao idoso, mas também ao seu cuidador.

Descritores: Enfermagem; Idoso; Assistência Domiciliária; Cuidadores.

\section{ABSTRACT}

It aimed to analyze the scientific production of Brazilian nursing, from 1979 to 2007, about the practices of the elderly's informal caregiver at home. This is a bibliographic review, with qualitative approach, developed in the period of June and July 2009 , that studied thesis and dissertations published in the Center of Studies and Researches in Nursing' catalogs. To analyze the data collected, it was used the thematic categorization system. From eleven works identified, four categories brought out: activities done by the caregiver, difficulties in the quotidian of care, feelings lived by the caregiver and knowledge and experiences of the caregiver. Knowledge of the work of these caregivers is critical for the actions of nurses and health team, addressing not only care for the elderly, but also of their caregivers.

Key words: Nursing; Elder; Home care; Caregiver.

\section{RESUMEN}

Se objetivó analizar la producción científica de la Enfermería brasileña, de 1979 a 2007, acerca de las prácticas del cuidador informal del anciano en el domicilio. Se trata de revisión bibliográfica, desarrollada en junio y julio de 2009, en que se estudió tesis y disertaciones publicadas en los catálogos del Centro de Estudios y Pesquisas en Enfermería (CEPEn). El abordaje fue cualitativo y se utilizó el sistema categorial temático para el análisis de los datos. De los once trabajos recogidos, se llegó a cuatro categorías: actividades realizadas por el cuidador, dificultades en el cotidiano del cuidar, sentimientos vivenciales del cuidador y conocimientos y experiencias del cuidador. El conocimiento de la actuación de esos cuidadores es de fundamental importancia para las acciones del enfermero y del equipo de salud, dirigiendo el cuidado no sólo al anciano, pero también al su cuidador.

Descriptores: Cuidadores; Anciano; Asistencia Domiciliaria.

\section{AUTOR CORRESPONDENTEＣhrystiany Plácido de Brito Vieira E-mail: chrystiany@bol.com.br}




\section{INTRODUÇÃO}

Nos últimos anos, em decorrência do aumento da expectativa de vida, vivencia-se, no Brasil e no mundo, um processo de envelhecimento populacional. Esse aumento da expectativa de vida é devido aos avanços na área da saúde, que têm possibilitado que cada vez mais pessoas consigam viver por um período mais prolongado, evidenciando-se a melhoria das condições sanitárias e de acesso a bens e serviços ${ }^{(1)}$. No entanto, esse processo de transição demográfica no Brasil ocorreu de forma rápida e desordenada sem que houvesse melhoria da qualidade de vida da população maior de 60 anos, ao contrário do que aconteceu nos países desenvolvidos ${ }^{(2)}$.

Diante dessas mudanças, observa-se que foram poucas as respostas do sistema de saúde e de outras políticas sociais, que tivessem como finalidade a saúde e o bem-estar do idoso. Esta constatação é preocupante, não só para o enfermeiro, mas para toda a sociedade brasileira, principalmente ao se analisar a condição social, econômica e de saúde da maioria da população da terceira idade, caracterizada por ser de baixo nível socioeconômico e potencialmente dependente dos serviços públicos de saúde.

Diante desse cenário, houve o despertar do Poder Público nas duas últimas décadas, fazendo parte essencial da Política Nacional de Saúde a implantação da Atenção Integral à População Idosa e aquela em processo de envelhecimento, em conformidade com o que determina a Lei Orgânica de Saúde, $\mathrm{n}^{\circ} 8.080 / 90$, e a Lei $\mathrm{n}^{\circ} 8.842 / 94$, regulamentada pelo Decreto $\mathrm{n}^{\circ} 1.948$, de três de julho de 1996, ao definir a atuação do governo, indicando as ações específicas das áreas envolvidas, e busca na criação de condições para a promoção da autonomia, integração e participação do idoso na sociedade, assim consideradas as pessoas com 60 anos ou mais. Segundo essa Lei, cabe ao setor saúde prover o acesso do idoso aos serviços e ações voltados à promoção, proteção e recuperação da saúde ${ }^{(3)}$.

Apesar dessa conquista política e social, observa-se que o Sistema Único de Saúde ainda não consegue atender a demanda no país, pois as políticas de proteção aos idosos não acompanharam as necessidades e os comprometimentos advindos do crescimento exponencial da população, já que a assistência a esse grupo deve ser pautada em questões multidimensionais e específicas e programada para a real e efetiva intervenção nos diferentes níveis de realidades e necessidades ${ }^{(4)}$.

Outra problemática referente ao envelhecimento populacional é o aumento do risco de doenças crônicas não transmissíveis que podem causar dependência e incapacidades. A doença crônica é o principal problema da população idosa, causando algumas limitações nas atividades de cuidados pessoais em $49 \%$ de todos os indivíduos idosos, e $27 \%$ apresentando dificuldades com a administração de casa, ocasionando a dependência ${ }^{(5)}$.

Diante da situação atual de envelhecimento demográfico, demandas são colocadas para a enfermagem, serviços de saúde, sociedade, poder público e família, exigindo modelos de apoio e assistência ao idoso dependente e incapacitado. Esses diferentes modelos estão sofrendo novas e grandes mudanças causadas pelas transformações nas relações sociais e pelo redirecionamento das funções de proteção e justiça social do Estado ${ }^{(6)}$.

Nos países desenvolvidos, tem-se observado uma tendência para a redução dos investimentos nos setores de saúde e de benefícios e para uma ampliação das responsabilidades familiares pelo sustento e assistência a esses idosos. No Brasil, ainda é muito restrita a oferta de serviços e intervenções, bem como programas de saúde pública. O Estado assume responsabilidades reduzidas, atribuindo à família do idoso dependente a responsabilidade maior, sem serviços de apoio ${ }^{(5)}$.

O cuidado no domicílio proporciona o convívio familiar, o apoio e a proteção que o idoso necessita ${ }^{(6)}$. No entanto, por se tratar da maioria possuir difíceis condições econômicas, o custo benefício torna-se oneroso, o qual, associado às condições sociais no contexto familiar, torna fundamental a existência concreta de uma rede de apoio ao idoso e família de forma sistematizada. Sabe-se que a Política Nacional ao Idoso tem como pressuposto básico a permanência do idoso com a família, no entanto reconhece que isso só é possível com recursos, infraestrutura e apoio disponível, definindo para tanto diretrizes que devem nortear todas as ações da saúde, e indicando a responsabilidade institucional ${ }^{(3)}$.

Isso demonstra a necessidade de apoio à família por outras instituições sociais, principalmente em contextos como o brasileiro, em que predominam as desigualdades sociais ${ }^{\left({ }^{8}\right)}$. Nesse contexto do cuidado domiciliar, surge a figura do cuidador informal. O cuidador informal, ao contrário do formal, é aquele que desempenha cuidado não profissional e seu papel sem receber nenhuma remuneração, podendo ser pessoas da família, amigos e vizinhos. Faz-se distinção também entre os cuidadores primários, secundários e terciários. Os cuidadores primários são os principais responsáveis pelo idoso e pelo cuidado e responsáveis pela maior parte das tarefas. Os secundários podem até realizar as mesmas tarefas, mas o que os diferencia dos primários é o fato de não terem o nível de responsabilidade e decisão, atuando quase sempre de forma pontual em alguns cuidados básicos, revezando com o cuidador primário. Os cuidadores terciários são coadjuvantes e não têm responsabilidade pelo cuidado, substituindo o cuidador primário por curtos períodos e realizando, na maioria das vezes, tarefas específicas como compras, pagar contas e receber pensões ${ }^{(5)}$.

Os familiares que assumem o papel de cuidadores informais podem entrar em situação de crise, cujos principais sintomas são: tensão, constrangimento, fadiga, estresse, frustração, redução do convívio, depressão e alteração da autoestima, entre outros $^{(9)}$. Esta sobrecarga ou tensão pode acarretar problemas físicos, psicológicos, emocionais, sociais e financeiros, que acabam por afetar o bem-estar do doente e do cuidador.

O grau de dependência do idoso influencia diretamente na família, pois a dependência em realizar suas Atividades da Vida Diária (AVD's) determina a necessidade de um cuidador que se disponibilize para auxiliá-lo. Os cuidadores subdividiram em AVDs a alimentação, integridade da pele, higiene, eliminações, terapêutica, locomoção e movimentação do paciente, e atividades instrumentais como preparar refeições, lavar e passar roupas, limpar a casa e realizar tarefas extradomiciliares ${ }^{(10,11)}$. 
As dificuldades das famílias para cuidar se relacionam aos obstáculos enfrentados pelos familiares durante o cuidado do idoso e ao enfrentamento de repercussões do adoecimento mediante incapacidades e/ou dependência total ou parcial para suas necessidades básicas no domicílio. Essa situação é agravada pela falta de orientações e informações que geram ansiedade no cuidador. O cuidador não recebe preparo para o cuidado, adquirindo habilidades e conhecimentos na prática diária ${ }^{(7,11)}$.

A compreensão para a atual assistência que vem sendo desenvolvida ao idoso nos serviços de saúde nos remete a admitir a vigência do modelo tradicional de saúde. As dificuldades são demonstradas por ações profissionais centradas no modelo curativo e individual que dificulta a realização de um atendimento baseado no coletivo e na minimização das necessidades da família ${ }^{(11)}$.

As difíceis condições econômicas, que acabam sendo uma das principais preocupações das famílias, refletem em enfrentamento que a família do idoso recebe para custear tratamento, reabilitação, serviços de cuidados no âmbito domiciliar.

Diante do exposto, o presente estudo teve como objetivo analisar o conhecimento produzido pela enfermagem brasileira em teses e dissertações, no período de 1979 a 2007, sobre as práticas do cuidador informal do idoso no domicílio. O conhecimento das práticas do cuidador informal desenvolvidas no domicílio poderá contribuir para as atividades educacionais da enfermagem e da equipe interdisciplinar, desenvolvidas nos mais diferentes ambientes e contextos de cuidado, procurando-se responder às necessidades dos cuidadores e dos idosos sob seus cuidados.

\section{METODOLOGIA}

Para alcançar as dimensões das práticas dos cuidadores informais de idosos no domicílio, produzidas pela Enfermagem brasileira, realizou-se uma pesquisa bibliográfica, desenvolvida a partir de teses e dissertações da Enfermagem brasileira de 1979 a 2007 que trabalharam com a temática. A pesquisa bibliográfica é utilizada pelos pesquisadores para apresentar resultados de estudos similares, relacionando o estudo presente ao diálogo corrente na literatura e fornecendo uma estrutura para comparar resultados de um estudo com outros ${ }^{(12)}$.

Para o desenvolvimento do estudo, buscou-se apreender os aspectos subjetivos relatados em dissertações e teses de enfermagem acerca das práticas que cuidadores informais de idosos no domicilio. A partir da definição da temática, em que foi traçado o objetivo, elaborou-se um plano de trabalho para a coleta dos dados. Escolheu-se a fonte de fornecimento dos dados adequados ao estudo e, após exaustivas leituras, deu-se início à análise e interpretação dos dados.

A fonte de dados escolhida foi o catálogo do Centro de Estudos e Pesquisas em Enfermagem (CEPEn), que possui o maior banco de dissertações e teses da Enfermagem brasileira. O CEPEn foi criado em 1971 pela Associação Brasileira de Enfermagem (ABEn) e está destinado à divulgação das pesquisas em enfermagem, organização e preservação de documentos históricos, sendo regido pelas disposições do Estatuto da
ABEn e do regimento do mesmo ${ }^{(13)}$.

Os critérios de inclusão foram: resumos de dissertações e teses de enfermagem, publicados no período de 1979 a 2007; utilização dos descritores cuidadores e idoso; abordagem da prática do cuidador informal no domicílio; e disponibilidade da produção completa.

A coleta dos dados ocorreu nos meses de junho e julho de 2009, utilizando-se formulário, constituído de duas partes. A primeira estava relacionada à caracterização do estudo: ano de publicação, instituição de ensino onde foi apresentado/ defendido, tipo e natureza do estudo, objetivos e descrição dos cuidadores. A segunda se referia à abordagem das práticas dos cuidadores, trabalhadas nas produções estudadas, levantando-se os aspectos abordados.

Inicialmente, foram identificados 36 resumos com os dois descritores. A partir da leitura dos resumos, identificou-se que apenas 23 atendiam ao critério da abordagem da prática do cuidador informal no domicílio. Desses, 12 não foram encontrados na sua versão na íntegra para se realizar a análise e, assim, o corpus do estudo ficou constituído por 11 dissertações e teses. Deve-se destacar que esse número de produções estava disponível na fonte de dados escolhida, o que não representa toda a produção dos programas de pós-graduação de enfermagem sobre a temática estudada, haja vista que existem enfermeiros realizando mestrado e doutorado em programas de pós-graduação de outras áreas.

Novamente, foi realizada uma leitura criteriosa dessas produções, principalmente dos objetivos, resultados, conclusões e/ou considerações finais. Em seguida, foi elaborado um quadro de convergências, divergências e complementaridades entre os estudos. Para a análise dos dados, escolheu-se a técnica de análise de conteúdo temática ${ }^{(14)}$, seguindo as etapas de pré-análise, exploração do material e tratamento dos resultados obtidos e interpretação. Nessa perspectiva, a construção das unidades temáticas deu-se após a leitura exaustiva dos trabalhos, o que possibilitou uma análise sob a perspectiva da análise de conteúdo, entrecruzando os autores, procurando nos fragmentos dos textos as convergências, divergências e complementaridades das produções divulgadas na base de dados pesquisada.

\section{RESULTADOS E DISCUSSÃO}

Os conteúdos que compõem essa parte do estudo se interrelacionam, no entanto, para fins de organização, os resultados e a discussão foram apresentados em dois momentos: caracterização das produções pesquisadas e as práticas de cuidadores informais de idosos no domicílio.

\section{Caracterização das produções pesquisadas}

Analisaram-se, no total, 11 dissertações e teses de enfermagem, produzidas no período de 1979 a 2007, os quais atenderam aos critérios de inclusão do estudo.

No quadro abaixo estão expostas as características desses trabalhos em relação ao ano de publicação, titulação, instituição de defesa e natureza do estudo. Quanto ao ano de publicação, observa-se que de 1979 a 1999 não houve registro nesse banco de dados de publicações de enfermagem 
abordando a prática do cuidador informal no domicílio. As tendências demonstram haver aumento na produtividade de trabalhos científicos, sinalizando aprofundamento na temática para as próximas décadas, sendo que no Brasil esse crescimento vem ocorrendo desde a segunda metade da década de 1990, quando aumentou o interesse pela família como sujeito do cuidado e pelas discussões das vantagens e sobrecargas em ser cuidador no domicílio ${ }^{(15)}$.

\begin{tabular}{|c|c|}
\hline Características & Produções \\
\hline \multicolumn{2}{|l|}{ Ano de Publicação } \\
\hline $1979|-| 1999$ & 0 \\
\hline $2000|-| 2003$ & 3 \\
\hline $2004 \mid-2007$ & 8 \\
\hline \multicolumn{2}{|l|}{ Titulação } \\
\hline Dissertação & 8 \\
\hline Tese & 3 \\
\hline \multicolumn{2}{|l|}{ Instituição de Defesa } \\
\hline Universidade Federal do Rio de Janeiro & 3 \\
\hline Universidade Federal de São Paulo & 2 \\
\hline Universidade Estadual de Maringá & 2 \\
\hline Universidade Federal de Santa Catarina & 2 \\
\hline Universidade Federal da Bahia & 1 \\
\hline Universidade Federal de Minas Gerais & 1 \\
\hline \multicolumn{2}{|l|}{ Natureza do estudo } \\
\hline Qualitativo & 7 \\
\hline Quantitativo & 3 \\
\hline Multimétodo & 1 \\
\hline
\end{tabular}

Quadro 1 - Caracterização das produções publicadas nos catálogos do CEPEn, de 1979 a 2007, quanto ao ano de publicação, titulação, instituição de defesa e natureza do estudo. Fortaleza-CE, 2009.

No Quadro 1, observa-se que das 11 produções publicadas nos catálogos do CEPEn no período de 1979 a 2007, nenhuma ocorreu no período de 1979 a 1999, mostrando assim lacuna no conhecimento de enfermagem. Nesse período, não havia concretização de uma política pública de proteção ao idoso, ocorrendo apenas em 1994 com o surgimento da Lei Orgânica de Saúde - N 8.080/90 - e a Lei 8.842/94, regulamentada pelo Decreto $N^{\circ} 1948$ de 03 de julho de 1996. Entende-se que somente a partir daí é que foram se dando o despertar para pesquisas relacionadas à saúde do idoso, na perspectiva do cuidado no domicilio.
Considera-se ainda o desenvolvimento da pós-graduação no país, e do aumento do número de programas de pós-graduação e cursos de doutorado na área de enfermagem. A existência de desigualdades regionais, tanto no número de doutores titulados, quanto nos de programas de pós-graduação oferecidos por esta área de conhecimento ${ }^{(16)}$, é percebida no estudo quando se verifica a concentração de produção nas regiões Sudeste e Sul do Brasil, por instituição acadêmica. Isto possibilita a deduzir que a distribuição da produção de enfermagem desigual se dá também por conta da concentração dos cursos de pós-graduação da área nas regiões Sul e Sudeste do país.

Quanto à natureza dos estudos de dissertação e tese, observa-se concentração de produções com abordagem qualitativa. Sabe-se que as pesquisas de enfermagem, nas últimas décadas, têm tido crescimento com abordagens subjetivas acerca do cuidado, no âmbito do individuo, família e comunidade.

No que se diz respeito aos objetivos dessas produções, relacionam-se a: compreender o que é cuidado tanto na perspectiva do idoso como do cuidador; conhecer as atividades desenvolvidas pelo cuidador; descrever as vivências de cuidadores familiares; identificar a rede de apoio existente; conhecer as implicações sobre o cuidador e a família e caracterizar esses cuidadores.

Quanto à caracterização dos cuidadores que participaram desses estudos, seguem o perfil encontrado na literatura que é o predomínio do sexo feminino e de laços de parentesco e de afetividade, representado principalmente por esposas e filhas, em processo de envelhecimento com idade variando entre 40 e 60 anos, com baixo nível de escolaridade, desempregadas ou dedicadas às atividades domésticas, com outros dependentes ${ }^{(6,17)}$

As práticas de cuidadores informais de idosos no domicílio

A análise do conteúdo das 11 dissertações e teses de enfermagem apontou quatro categorias temáticas referentes à prática do cuidador informal de idoso no domicílio: atividades realizadas pelo cuidador, dificuldades no cotidiano do cuidar, sentimentos vivenciados pelo cuidador e conhecimentos e experiências do cuidador.

\section{Atividades realizadas pelo cuidador}

A atividade de cuidador integra a Classificação Brasileira de Ocupações - CBO, sob o código 5.162, que define cuidador como alguém que cuida a partir de objetivos estabelecidos por instituições especializadas ou responsáveis diretos, podendo ser da família ou da comunidade para prestar cuidados à outra pessoa de qualquer idade que esteja necessitando ${ }^{(1)}$.

A função do cuidador é acompanhar e auxiliar a pessoa cuidada, fazendo por ela somente aquilo que ela não consiga fazer sozinha, não fazendo parte de sua rotina técnicas e procedimentos característicos de profissões legalmente estabelecidas, particularmente na área de enfermagem ${ }^{(1)}$.

Dentre as principais atribuições do cuidador informal, têm-se: atuar como elo entre a pessoa cuidada, a família e a equipe de saúde; escutar e ser solidário com a pessoa cuidada, ajudar nos cuidados de higiene; estimular e ajudar na alimentação; ajudar na locomoção e atividades físicas; estimular atividades 
de lazer e ocupacionais; realizar mudanças de posição na cama e na cadeira, e massagens de conforto; administrar as medicações, conforme a prescrição e orientação da equipe de saúde; comunicar à equipe de saúde sobre mudanças no estado de saúde da pessoa cuidada; outras situações que se fizerem necessárias para a melhoria da qualidade de vida e recuperação da saúde dessa pessoa ${ }^{(1)}$.

Destaca-se que essas atividades devem ser planejadas pela equipe de saúde de acordo com as necessidades do idoso e do cuidador, devendo ser esclarecidas as responsabilidades de cada um.

Dentre as 11 produções estudadas as atividades dos cuidadores informais foram levantadas em seis delas ${ }^{(18-23)}$. Com cuidadores de idoso com Alzheimer, foram identificadas as seguintes atividades: higiene corporal, alimentação, acompanhamento e vigilância, escovação dos dentes, cuidado dos cabelos, cuidado com roupas e comunicação, destacando que são contínuos e centralizados em uma única pessoa ${ }^{(19)}$.

Os cuidados dispensados ao idoso, no caso portador de demência, envolvem a manutenção das atividades de vida diária, como também ações que buscam manter não somente a integridade física, mas também a moral através do estabelecimento e manutenção de comunicação com esse idoso e da estimulação da sua interação com o seu ambiente ${ }^{(19)}$.

Nota-se que o papel do cuidador ultrapassa o simples acompanhamento das atividades de vida diária do idoso, principalmente se esse idoso apresenta uma doença crônico-degenerativa não transmissível, como a Doença de Alzheimer.

A partir da quantidade expressiva de referências aos cuidados direcionados à saúde dos idosos, às práticas dos mesmos no controle do estado de saúde do idoso, está a disponibilidade do cuidado familiar que significa que os familiares exercem um controle sobre o estado de saúde do idoso, por perceberem o declínio de certas habilidades funcionais. Esse controle se manifesta mediante práticas de vigilância, de intervenção nos hábitos de vida dos entrevistados, ou pela evocação de atitudes responsáveis, direcionadas ao desempenho satisfatório do idoso voltado ao autocuidado ${ }^{(20)}$.

Quanto aos idosos acometidos por acidente vascular cerebral, verificou-se em estudo que as principais tarefas realizadas pelo cuidador familiar de idoso com acidente vascular cerebral no domicílio são: higiene no leito, no chuveiro, higiene genital, do cabelo e oral; troca de roupa; prevenção de úlcera de decúbito; mudança de decúbito; troca de fraldas; preparo da alimentação; auxílio na alimentação via oral; administração de alimentação por sonda nasogástrica; administração de medicação; controle do horário da medicação; prevenção de queda; auxílio na deambulação; auxílio no uso de equipamentos; estímulo a exercícios físicos; estímulo atividades de lazer; acompanhamento de consultas médicas ${ }^{(20)}$.

Destas, a atividade mais citada $(97,1 \%)$ pelos cuidadores foi o acompanhamento do idoso às consultas médicas, sendo esse momento visto como de grande importância e grande responsabilidade para o cuidador, que recebe as orientações médicas e condutas necessárias para cuidar, cabendo a ele viabilizá-las ${ }^{(20)}$.

E, por detrás da condição clínica apresentada, também se evidenciam relações de poder e de saber. De um lado, o cuidador principal, que é quem está investido de poder no cuidado do doente (é quem decide o que deve ser feito e providencia para que seja feito) e de outro, o médico, que detém o conhecimento da doença e de seu tratamento. Então, parece compreensível condutas necessárias para cuidar, já que a responsabilidade de viabilizá-las cabe a ele $e^{(20)}$.

Foi constatada também a centralização das atividades em uma única pessoa, denominada cuidador primário. As relacionadas ao sono e repouso, e atividade física são aquelas em que o cuidador não recebe ajuda de outras pessoas, e ao retorno às consultas, alimentação e medicação, quase sempre ou sempre recebe ajuda ${ }^{(21)}$.

Quando se investigam as atividades realizadas pelos cuidadores informais, que podem necessitar de maior ou menor envolvimento desses cuidadores de acordo com o nível de dependência do idoso, constata-se nessas produções pesquisadas que se consegue identificar quais são as atividades e a freqüência, mas é difícil se dimensionar o envolvimento exigido, o que pode não refletir a real situação do cotidiano desses cuidadores. Essa limitação pode ser exemplificada na realização de higiene corporal.

Esta pode ser realizada no leito ou no chuveiro. A realização do banho no leito geralmente demanda da pessoa que o está realizando esforço físico, organização e intimidade, independente de o paciente ser totalmente dependente ou poder colaborar de alguma forma, enquanto que para o banho no chuveiro pode ser necessária a execução em si, a qual implica, todavia, menor desgaste que no leito, o auxílio com as partes do corpo mais difíceis ou apenas a supervisão. Assim, conceber que todas as atividades envolvem o mesmo nível de dificuldade pode descaracterizar o trabalho dos cuidadores ${ }^{(18)}$.

Destacam-se também como atividades realizadas pelos cuidadores informais a higiene corporal, alimentação, cuidado com a integridade física, medicação e vestuário, denominadas de cuidados fundamentais ${ }^{(22,23)}$.

Assim, nesses termos, o cuidado fundamental é aquele que está tanto no campo do técnico, quanto do sensível. No seu bojo, estão os cuidados inerentes à medicação, à higiene, à atividade física, ao conforto, à segurança física, à alimentação, ao vestuário, além da necessidade de diálogo, de atenção, da demonstração de zelo e afeto, entre outros indispensáveis à relação do cuidado e que estão na esfera do sensível. Ou seja, são cuidados que abrangem o território domiciliar e também o profissional, cujo conhecimento, é de domínio da enfermeira e está presente na prática do familiar no domicílio(22). 
Os cuidados também podem ser classificados em: de manutenção (alimentação, higiene corporal, vestuário, integridade física, entre outros) e de reparação (oferecer medicação). Os cuidados de manutenção são mais predominantes e estão relacionados à incapacidade funcional do idoso e os cuidados de reparação visam o tratamento da doença. Esses cuidados são dos mais simples aos mais complexos, como o banho e o transporte que exigem do cuidador um esforço físico constante e a medicação, certo grau de escolaridade ${ }^{(23)}$.

$\mathrm{O}$ ato de cuidar é complexo e envolve as mais variadas atividades, que devem ser bem planejadas pelos profissionais de saúde. Neste contexto, destaca-se o papel do enfermeiro em parceria com o cuidador para possibilitar a sistematização das tarefas a serem realizadas no domicílio, privilegiando-se aquelas relacionadas à promoção da saúde, à prevenção de incapacidades e à manutenção da capacidade funcional do idoso e do próprio cuidador.

\section{Dificuldades no cotidiano do cuidar}

Assumir o cuidado de um idoso, geralmente sozinho, não é uma tarefa fácil, pois o cuidador se vê obrigado a agregar novas atividades a sua rotina de vida. Várias dificuldades podem surgir no cotidiano do cuidador, relacionadas à dinâmica familiar, à demanda de cuidados, aos gastos financeiros, entre outro. As dificuldades enfrentadas por cuidadores foram abordadas em sete dos 11 trabalhos levantados ${ }^{(18,23-28)}$.

Em outro estudo, surgiram diferentes graus de dificuldades, pois cuidar de idoso, principalmente com necessidades especiais, exige do cuidador tarefas contínuas e duradouras, além de atividades que oferecem atenção, amor, carinho e apoio emocional. Dentre as dificuldades mais relatadas, estão as que exigem esforço físico. Soma-se a essa dificuldade a necessidade do cuidador de dividir o seu tempo com outras atividades domésticas, desencadeando-lhe uma situação de desgaste físico e emocional ${ }^{(23)}$.

A dificuldade de realizar os cuidados no período noturno também foi apontada, tendo em vista a necessidade de descanso do cuidador, o qual é impedido por ter que continuar realizando os cuidados ao idoso, o que aumenta ainda mais o desgaste físico e mental, manifestado por insônia ${ }^{(19)}$. Vale a pena destacar que essas dificuldades são acentuadas, em virtude da falta de adequação do espaço físico do domicílio ao cuidado, o que aumenta o risco de acidentes e quedas, comprometendo a saúde do idoso e os esforços físicos dos cuidadores para executar as tarefas.

As dificuldades manifestadas pelos cuidadores não são específicas das atividades da vida diária ao cuidado, podendo expressar questões de suas próprias subjetividades, relacionadas aos sentimentos e à dinâmica familiar. Em estudo sobre a temática, os cuidadores ao serem questionados sobre as dificuldades enfrentadas, responderam que tiveram dificuldades somente no início ${ }^{(18)}$.

Assim, quando indagados sobre as dificuldades enfrentadas na realização dos cuidados, refletem além da simples pergunta e pensam exatamente sobre aquilo que para eles significa dificuldade. Passado o primeiro impacto de ter que cuidar em casa, muitas dificuldades ao realizar alguma atividade tornam-se insignificantes frente à falta de dinheiro para comprar remédios, alimentos, cadeira de rodas etc. Esta análise pode explicar porque vários cuidadores responderam que não têm dificuldade para realizar os cuidados. Afirmaram que tinham dificuldades no início, quando iniciaram a cuidar, mas agora já as superaram ${ }^{(18)}$.

A subjetividade também se faz presente nos medos e constrangimentos vivenciados na execução de algumas tarefas, como na realização do banho.

Pode-se inferir que nem sempre o banho em si significa uma tarefa difícil. A verdadeira dificuldade está em romper com valores arraigados desde a infância do cuidador e que representam invadir a privacidade e a intimidade do outro, que é seu pai, mãe, sogro, e que, até então, ver ou tocar estes corpos era totalmente não aceito como natural, ou seja, era proibido ${ }^{(18)}$.

Portanto, a realização da higiene corporal requer do cuidador, não apenas conhecimento e orientação de como efetuá-la, mas também preparo e habilidade emocional para lidar com situações subjetivas inerentes ao processo de cuidar.

Além das dificuldades relacionadas às atividades e aos aspectos subjetivos, há também as dificuldades relacionadas à família(19). Com isso, na maioria das vezes, os cuidados são centralizados em apenas um cuidador, o qual fica sobrecarregado ao assumir as responsabilidades e decisões.

Outra dificuldade apontada nos estudos realizados sobre cuidadores é a falta de apoio tanto formal como informal, sendo esse fornecido por familiares, amigos e vizinhos, que supre principalmente as necessidades emocionais, financeiras e instrumentais, e o formal, representado por serviços e profissionais de saúde, que propiciam atendimento domiciliar, transporte e fornecimento de materiais.

Verificou-se, em estudo dissertativo acerca de sentimentos, saberes e fazeres do cuidador principal do idoso com câncer, que o apoio recebido pelos cuidadores era insuficiente, desarticulado e não respondia às necessidades do cuidado ${ }^{(24)}$.

Os múltiplos papéis e funções como mãe, esposa, cuidadora e dona de casa desenham uma realidade que exigiria a ajuda de outra pessoa, mas nem sempre é possível pagar alguém para ajudar e por outro lado, não contam com ajuda regular da rede informal e formal. Assim sendo, é imposto à cuidadora uma sobrecarga que se torna maior em presença de distúrbios comportamentais do idoso ou em situações que se sentem inseguras para tomar decisões ${ }^{(24)}$.

A necessidade de apoio é definida a partir de dois critérios: em primeiro lugar, a partir da relação entre o tipo de cuidado que tem que desenvolver e a capacidade de executá-lo sozinha ou não e, em segundo lugar, pelo grau de dependência do idoso, pois à medida que o grau de dependência do idoso se agrava, aumenta o investimento físico e emocional no desenvolvimento do cuidado ${ }^{(24)}$. 
Observa-se nos relatos dos estudos aqui apreciados, que as dificuldades se acentuam quando há comprometimento cognitivo do idoso, causados por patologias como a depressão, o acidente vascular cerebral e o mal de Alzheimer. Essas alterações dificultam a execução do cuidado, ocasionando insegurança e estresse nos cuidadores informais.

A falta de informações sobre a patologia do idoso foi apontada como fator gerador de dificuldades no cuidado ${ }^{(25)}$.

A trajetória desses familiares, como cuidadores informais com escassos conhecimentos e informações acerca da Doença de Alzheimer, com demandas econômicas e a inexistência de contrapartida adequada por parte do sistema formal de saúde, sinalizava a necessidade imediata de receberem apoio para enfrentar a situação de vida em que se encontravam ${ }^{(25)}$.

Esses dados reforçam a necessidade de orientação desses cuidadores quanto aos sintomas das doenças que acometem os idosos no domicílio, bem como as condutas que devem ser adotadas. A atenção na preparação dos cuidadores faz-se necessária a recuperação do idoso, além de proporcionar apoio técnico e emocional àqueles que irão assumir o papel de cuidador de forma mais segura à saúde física, emocional e social do idoso no contexto domiciliar.

\section{Sentimentos vivenciados pelo cuidador}

$\mathrm{O}$ ato de cuidar significa vivenciar uma diversidade de sentimentos, geralmente ambivalentes. O que motiva o cuidado, independente de se gostar ou não, está relacionado a um sentimento, que se denominou de um "chamado", e a uma compulsão para ajudar a quem necessita no sentido do bem ${ }^{(26)}$.

A relação dos sentimentos dos cuidadores como dificuldade expressa pelos mesmos está relacionada à dinâmica familiar ${ }^{(20)}$.

Isto pode ser evidenciado quando uma cuidadora referiu a dificuldade encontrada em estruturar os papéis familiares. Até seu marido adoecer ela era uma mulher que se dedicava à casa e a família. Após a doença do marido, precisou assumir o gerenciamento do orçamento doméstico e tomar decisões ${ }^{(18)}$.

A diversidade e intensidade de sentimentos vivenciados pelos cuidadores ocorrem devido ao envolvimento afetivo proporcionado pelos laços familiares dos cuidadores com os idosos, sendo o cuidado uma forma de, por exemplo, filhas cuidadoras retribuírem a oportunidade de terem sido geradas e postas no mundo, isto é, já forma objetos de cuidado de seus idosos. Nesse sentido, os cuidadores vêem-se tomados por um misto de sentimentos - retribuição, amor e satisfação, medo e impaciência - ao prestar os cuidados aos idosos que, quando gozavam de independência e autonomia, dedicaram-lhes cuidado, amor e atenção, tomando para si o papel de pai e de tia amáveis, de esposo e de avó que assumiram o cuidado quando outros da família o negaram ${ }^{(27)}$.

Esse sentimento de retribuição de cuidados ao idoso também foi considerado positivamente, pois o cuidar para alguns cuidadores, foi relatado em estudo dissertativo acerca do apoio social ao cuidador familiar do idoso dependente. Verificou-se que esse foi desenvolvido com muito amor, atenção, carinho e prazer, sendo o mesmo influenciado pelo reconhecimento, obrigação e dever relacionados aos bons momentos vivenciados junto ao idoso e também uma retribuição de sentimentos acumulados durante a trajetória de vida do idoso com o cuidador ${ }^{(23)}$.

Além dos sentimentos de retribuição, destacam-se também os sentimentos de satisfação com a recuperação do idoso, tristeza e pena pela dependência do idoso e os sentimentos desencadeados pela sobrecarga que representa ao cuidador no domicilio ${ }^{(27)}$.

Os sentimentos gerados também decorrem da convivência com as limitações impostas pelas doenças degenerativas do idoso, apresentados em pesquisa sobre a vivência de familiares cuidadores de idosos com Alzheimer, em que se constatou que conviver com esse doente proporciona ao cuidador variadas sensações, desencadeando situações conflitantes carregadas de tensão e dilemas no cuidar. Muitos familiares apresentam dificuldades nesse convívio, pois precisam ser compreendidos no entendimento e aceitação da doença para então, reconstruir o significado de seu familiar como doente. Frequentemente, na rotina de cuidados com o doente e suas limitações impostas pela doença, o familiar cuidador fica visivelmente abalado e é comum a perda da paciência, seja pelos erros, repetições ou mesmo pelo humor do doente ${ }^{(22)}$.

A ambiguidade de sentimentos do cuidador junto ao idoso doente desencadeia conflitos intrafamiliares, pois o cuidador pode se sentir em desvantagem por adiar seus projetos de vida, gerando sentimentos de frustração.

Como o cuidador ao assumir o cuidado de um familiar sozinho lida com uma diversidade de sentimentos e agrega novas atividades a sua rotina de vida, destaca-se a importância do suporte social, representado principalmente pela família, mas também podendo ser oferecido por vizinhos, amigos e pela rede formal ${ }^{(28)}$.

Os sentimentos relacionados ao cuidado do idoso com câncer, destacando que os mesmos estariam mais ligados à história de vida do cuidador, aos motivos pelos quais assumiu o papel, à qualidade do relacionamento com o idoso e ao suporte disponível do que propriamente ao grau de dependência do idoso(24).

A falta de apoio informal e formal é motivo de sobrecarga e geração de sentimentos que dificultam o desenvolvimento do cuidado. Verificou-se que cuidadores discorrem nitidamente sobre a questão das pressões derivadas da escassez de suporte informal e formal. Vários fatores contribuem para isso: os amigos querem ajudar, mas não se organizam para tal e por outro lado, a pouca confiança das cuidadoras com relação à capacidade de eles desenvolverem cuidados diretos complexos, pois não se sentem confortáveis quando os delegam porque consideram isso de seu domínio e obrigação ${ }^{(24)}$.

Por sua vez, a família centraliza as responsabilidades na mulher, cuidadora principal e subestima suas necessidades pessoais e o sistema formal não oferece ajuda adequada. A ambivalência de sentimentos consequentemente está presente 
no cotidiano desses cuidadores que procuram atender as necessidades do idoso impostas pela incapacidade funcional deles, motivados pelo sentimento de amor, retribuição, prazer e satisfação $^{(24)}$.

No entanto, a vivência de dificuldades e o sofrimento físico e mental resultam em sentimentos que os desmotivam. Pois, ao mesmo tempo em que a cuidadora adquire capacidade de lidar com procedimentos cada vez mais complexos, como por exemplo, cuidar de uma pessoa com traqueostomia, experimenta um desgaste muito grande que se traduz em dificuldade para organizar-se e dar conta do acúmulo de atribuições pelas quais é responsável. Diante da impossibilidade de transformar essa situação, a cuidadora experimenta sentimentos de impotência que acabam afetando a autoestima e a sua saúde(24).

Em outra investigação sobre o cuidado domiciliário de idoso com demência, os depoimentos dos cuidadores foram relacionados aos sentimentos decorrentes do medo de exagerar nos cuidados, das mudanças comportamentais do idoso impostas pela doença, da inversão de papéis e da dependência do idoso, que representam as subjetividades do cuidar/ cuidado ${ }^{(27)}$.

Lidar com questões internamente desconhecidas e principalmente (re)conhecer a deterioração de capacidades intelectuais de um indivíduo coparticipante de nossas histórias, o qual muitas vezes possui um significado em nossas vidas, exige dos cuidadores "atenção interna" persistente e contínua para "con-viver" e (re)significar sentimentos, atitudes, valores, ou até mesmo, (re)significar a vida ${ }^{(19)}$.

Observa-se que o conhecimento dos sentimentos vivenciados pelo cuidador informal é um elemento muito importante para se compreender o processo de cuidar na perspectiva do cuidador, pois dessa forma pode-se tentar minimizar o impacto da situação de cuidar de um idoso, muitas vezes dependente, e amenizar a intensidade e a diversidade de sentimentos que surgem durante o exercício dessa complexa atividade.

\section{Conhecimentos e experiências do cuidador}

Cuidar é uma ação e um comportamento que envolve conhecimento, valores, habilidades e atitudes empreendidas no sentido de favorecer as potencialidades das pessoas para manter ou melhorar a condição humana no processo de viver ou morrer. O cuidado é inerente ao ser humano, por isso, cuidar de alguém requer do cuidador habilidades que acabam se expressando no cotidiano do cuidado ${ }^{(26)}$. Além disso, os problemas gerados na família e para o cuidador informal decorrentes do cuidado de idoso no domicílio com algum grau de dependência resulta na busca da reorganização para alcançar o equilíbrio, por meio de estratégias que possam garantir o enfrentamento dessas situações.

Os conhecimentos e experiências dos cuidadores informais foram identificados em quatro trabalhos ${ }^{(22,25,29,30)}$.

Cuidar de um idoso com Alzheimer impõe ao cuidador familiar uma realidade que evidencia características particulares de seus saberes e fazeres, que a partir do não-saber e das influências sócio-culturais constrói um saber por meio da experiência determinada pela prática cotidiana. O conhecimento dos cuidadores é construído também na interação desses cuidadores com outros cuidadores, isto é, na fala social uns com os outros, nas diversas formas de cuidado realizado com outros na construção de suas vidas, como também com os profissionais de saúde, sendo permeado pelo conhecimento científico $^{(22)}$.

A dimensão prática dos cuidados junto ao familiar doente no domicílio se ampara nos saberes e práticas dos familiares construídos no universo sócio-familiar, a partir de suas experiências concretas que de alguma forma foram válidos em determinados momentos. Ao buscarem o espaço institucional, esses familiares foram incorporando novos saberes e práticas, passando a lançar mão dos mesmos e a intermediá-los com os seus, perpassando suas ações por esses dois universos: o senso comum e o científico ${ }^{(22)}$.

Também foi destacado em estudo acerca dos sentimentos, saberes e fazeres do cuidador principal de idoso com câncer que os cuidadores informais desempenhavam o cuidado ao idoso sob as perspectivas do cuidador denominado por formal, informal e popular, atualizando práticas e saberes, repassados de geração a geração por meio do sistema formal, e resgatando práticas de cuidado que foram deixadas de lado ou esquecidas no sistema informal(25).

Observou-se ainda que, de modo geral, as práticas de cuidado das cuidadoras principais de idosos com câncer eram perpassadas principalmente por três campos de conhecimentos, os biomédicos, os informais e os populares, esses saberes ora se sobrepõem, ora entram em conflito, como também chegam a integrar-se e combinar-se estabelecendo condições ideais de cuidado ${ }^{(25)}$.

As práticas terapêuticas formais estão relacionadas às crenças dos cuidadores sobre o processo saúde-doença e contextualizadas pelo tipo de vínculo com o idoso. Como práticas informais de cuidado, destacam-se a automedicação alopática, o uso de remédios naturais, a valorização de cuidados básicos. Os cuidadores relataram ainda que o dom para cuidar é um estilo próprio, isto é, o conhecimento e a experiência singular de cada cuidador. Nessa pesquisa, o autor pode testemunhar a diversidade de modos de cuidar que eles compartilhavam; relatando aos novos integrantes do grupo que não existe uma receita pronta que ensine como cuidar - é preciso ser criativo. Desse modo, cada cuidador, orientado pelo seu estilo, 'inventava' uma maneira de cuidar que Ihe parecia melhor ${ }^{(25,30)}$.

Também, observou-se a importância dos saberes e práticas dos cuidadores informais como estratégias para minimizar os gastos econômicos do cuidar, motivo de dificuldade apresentada pelas famílias que cuidam de idosos dependentes, principalmente em um contexto como o brasileiro marcado pelas desigualdades sociais. As cuidadoras, ao buscar a economia de custos de tempo e de esforço físico, utilizaram a criatividade para o desenvolvimento de técnicas adequadas. Essas técnicas permitiram agilizar as tarefas e deixar tempo 
disponível para outras atividades. Outro fator positivo é a economia financeira proveniente dessas estratégias de cuidado. Além dessa economia que pode ser mensurada, destaca-se a prevenção de custos que ocorrem em situações de agravos ${ }^{(30)}$.

Os cuidadores informais conseguem integrar em suas práticas diferentes princípios que contribuem com o bem-estar do idoso. Esse resgate do cuidado domiciliar gera uma resignificação do ambiente domiciliário, tão ligado ao sofrimento, tornando-o um espaço positivo de crescimento e satisfação pessoal, procurando estratégias que lhe permitam enfrentar crises e situações estressantes.

\section{CONSIDERAÇÕES FINAIS}

O presente estudo possibilitou verificar que a Enfermagem tem ampliado conhecimentos na área de atenção ao idoso, desenvolvendo estudos aprofundados e contextualizados com a política nacional do país, que a partir do aumento do enveIhecimento populacional, tornou-se área de interesse para a pesquisa, ensino e assistência no sistema de saúde.

A análise da produção científica mostrou a inserção do enfermeiro no contexto da assistência domiciliária que se encontra em ascensão, com resgate da família para compor o modelo de saúde idealizado e em desenvolvimento nas diversas regiões do Brasil, fazendo-se presente nos segmentos dos serviços públicos e privados existentes.

Evidenciou-se que, a partir dos saberes e práticas dos cuidadores informais de idosos desenvolvidos no domicílio, o enfermeiro, junto com a equipe de saúde, busca estratégias educativas na assistência domiciliaria, em que o cuidado deve ir além do estado de saúde do idoso, tendo foco de atenção a saúde do cuidador, sua percepção e estratégias de cuidar, as necessidades e dificuldades, o conhecimento das experiências de cuidado.

As atividades diárias junto ao idoso são muitas e das diversas dimensões, contínuas e relacionadas ao atendimento das necessidades de saúde do mesmo, sendo de acordo com o grau de dependência, limitações funcionais e cognitivas do idoso. Assim, o cotidiano do cuidado traz dificuldades de ordem emocional, física, econômica e social para o cuidador, fazendo-se necessária a assistência e apoio de profissionais de saúde na família.

Mas, apesar das dificuldades, os estudos analisados permitiram reconhecer que os cuidadores desempenham um novo papel a partir da adaptação à situação imposta pela dependência do idoso, desenvolvendo o cuidado a partir de conhecimentos e experiências próprias, que são aprimorados por meio de esforços particulares, segundo as condições estruturais que possuem e ao mundo de vida a que pertencem. No entanto, as pesquisas mostram que os mesmos se sentem despreparados para o cuidado no domicilio, devendo a enfermagem e demais profissionais ampliar estratégias para o apoio, acompanhamento e capacitação dos mesmos.

Assim, deve-se pensar na formação do enfermeiro com interdisciplinaridade, incluindo conteúdos que venham fortalecer a preparação na atenção à inclusão da família para o cuidado do idoso no domicilio.

\section{REFERÊNCIAS}

1. Ministério da Saúde (BR). Secretaria de Atenção à Saúde. Secretaria de Gestão do Trabalho e da Educação na Saúde. Guia prático do cuidador. Brasília: Ministério da Saúde; 2008.

2. Cerqueira ATAR, Oliveira NIL. Programa de apoio a cuidadores: uma ação terapêutica e preventiva na atenção à saúde dos idosos. Psicologia da USP 2002; 13(1): 133-50.

3. Brasil, Ministério da Saúde. Política Nacional do Idoso: perspectiva governamental. Brasília, DF: Seminário Internacional Envelhecimento Populacional: uma agenda para o final de século, 1996.

4. Fonseca AM. O cuidado domiciliário ao idoso com doença de Alzheimer: um enfoque ao cuidador [dissertação]. Rio de Janeiro (RJ): Centro de Ciências Biológicas e da Saúde, Universidade Federal do Estado do Rio de Janeiro; 2007.

5. Eliopoulos C. Enfermagem gerontológica. $5^{\mathrm{a}}$ ed. Porto Alegre: Artmed; 2005.

6. Karsch UM. Idosos dependentes: famílias e cuidadores. Cad Saúde Pública 2003; 19(3): 861-6.

7. Thober E, Creutzberg M, Viegas K. Nível de dependência de idosos e cuidados no âmbito domiciliar. Rev Bras Enferm 2005; 58(4): 438-43.

8. Angelo M. O contexto familiar. In: Duarte YAO, Diogo $\mathrm{MJE}$, organizadores. Atendimento domiciliar: um enfoque gerontológico. São Paulo: Editora Atheneu; 2000. p. 27-31.

9. Martins T, Ribeiro JP, Garret C. Estudo de validação do questionário de avaliação da sobrecarga para cuidadores informais. Psicologia, Saúde \& Doença 2003;4(1):131-48.

10. Machado ALG, Jorge MSB, Freitas CHA. A vivência do cuidador familiar de vítima de acidente vascular encefálico: uma abordagem interacionista. Rev Bras Enferm, 2009; 62(2): 246-51.

11. Marcon SS, Lopes MCL, Fernandes J, Antunes CRM, Waidman MAP. Famílias cuidadoras de pessoas com dependência: um estudo bibliográfico. Online Braz J Nurs [periódico na Internet]. 2006 [citado 2006 jan. 20]; 5(1). Disponível em: http://www.uff.br/objnursing/index.php/ nursing/rt/printerFriendly/145/40.

12. Creswell JW. Projeto de pesquisa: métodos qualitativo, quantitativo e misto. $2^{\mathrm{a}}$ ed. Porto Alegre: Artmed; 2007. 
13. Leite JL, Oliveira DC. Centro de estudos e pesquisas em enfermagem e a Aben: 80 anos de desafios. Rev enferm UERJ 2006; 14(2): 161-2.

14. Bardin L. Análise de conteúdo. Lisboa: Edições 70; 2004.

15. Bocchi SCM. Vivenciando a sobrecarga ao vir-a-ser um cuidador familiar de pessoa com acidente vascular cerebral (AVC): análise do conhecimento. Rev Lat Am Enfermagem 2004;12(1):115-21.

16. Rodrigues RAP, Erdmann AL, Silva IA, Fernandes JD, Araújo TL, Vianna LAC, et al. Educação do doutorado em enfermagem no Brasil. Rev Lat Am Enfermagem 2008;16(4):665-71.

17. Fonseca NR, Penna AFG. Perfil do cuidador familiar do paciente com seqüela de acidente vascular encefálico. Ciênc Saúde Coletiva 2008; 13(4): 1175-80.

18. Perlini NMOG. Cuidar de pessoa incapacitada por acidente vascular cerebral no domicílio: o fazer do cuidador familiar [dissertação]. São Paulo (SP): Escola de Enfermagem, Universidade de São Paulo; 2000.

19. Fonseca AM. O cuidado domiciliário ao idoso com doença de Alzheimer: um enfoque ao cuidador [dissertação]. Rio de Janeiro (RJ): Centro de ciências biológicas e da saúde, Universidade federal do estado do rio de janeiro; 2007.

20. Domingos AM. Cuidado familiar como questão do enveIhecimento da enfermagem gerontológica [tese]. Rio de Janeiro (RJ): Escola de Enfermagem Anna Nery, Universidade Federal do Rio de Janeiro; 2003.

21. Gratão ACM. Demanda do cuidador familiar com idoso demenciado [dissertação]. Ribeirão Preto (SP): Escola de Enfermagem de Ribeirão Preto, Universidade de São Paulo; 2006.

22. Coelho GS. Fundamental no cuidado junto ao idoso com Alzheimer: vivências e experiências de familiares cuidadores compartilhadas no diálogo grupal [dissertação]. Rio de Janeiro (RJ): Escola de Enfermagem Anna Nery, Universidade Federal do Rio de Janeiro; 2004.

23. Nardi EFR. Apoio social ao cuidador familiar do idoso dependente [dissertação]. Maringá (PR): Departamento de Enfermagem, Universidade Estadual de Maringá; 2007.

24. Vieira MCU. Sentimentos, saberes e fazeres do cuidador principal do idoso com câncer [dissertação]. Maringá (PR): Departamento de Enfermagem, Universidade Estadual de Maringá; 2006.

25. Pelzer MT. Assistência cuidativa humanística de enfermagem para familiares cuidadores de idosos com doença de Alzheimer a partir de um grupo de ajuda mútua [tese]. Florianópolis (SC): Departamento de Enfermagem, Universidade Federal de Santa Catarina; 2005.

26. Waldow VR. Cuidado humano: o resgate necessário. Porto Alegre: Sagra Luzzato; 1998.

27. Lavinsky AE. Cuidar de idosos com acidente vascular encefálico: representações de familiares cuidadores [dissertação]. Salvador (BA): Departamento de Enfermagem, Universidade Federal da Bahia; 2001

28. Mendonça FF, Garanhani ML, Martins VL. Cuidador familiar de sequelados de acidente vascular cerebral: significado e implicações. Physis 2008; 18(1): 143-58.

29. Rates HF. Cuidado de saúde do idoso, no domicílio: implicações para as cuidadoras, no Distrito Ressaca - Município de Contagem/MG [dissertação]. Belo Horizonte (MG): Escola de Enfermagem, Universidade Federal de Minas Gerais; 2007.

30. Sena ELS. Experiência do outro nas relações de cuidado: uma visão merleaupontyana sobre as vivências de familiares cuidadores de pessoas com doença de Alzheimer [tese]. Florianópolis (SC): Centro de Ciências em Saúde, Universidade Federal de Santa Catarina; 2006. 